\title{
Prevalence of Functional Gastrointestinal Disorders in School Children and Adolescents
}

\author{
Juan Javier Peralta-Palmezano and Rafael Guerrero-Lozano \\ Department of Pediatrics, Universidad Nacional de Colombia, Bogotá, Colombia
}

Background/Aims: The epidemiology of functional gastrointestinal disorders (FGIDs) in developed and developing countries involves a high prevalence of constipation and irritable bowel syndrome. This study examined the prevalence of functional gastrointestinal disorders in schoolchildren and adolescents in Colombia using the Rome III criteria.

Methods: A cross-sectional study was performed on Colombian children between 8 and 17 years old. The Spanish version of the Questionnaire on Pediatric Gastrointestinal Symptoms-Rome III Version self-report form was answered by students from two schools. The prevalence of FGID was calculated and correlation tests were conducted among the variables analyzed.

Results: A total of 864 children with a mean age of $12.5 \pm 2.5$ years were analyzed; $50.7 \%$ were female. Two hundred and fifty-nine children (30\%) had at least one FGID, and of these, 163 were female (62.9\%). Sixty-nine children had two or more FGIDs (8\%). Functional constipation was the most prevalent disorder (13.2\%), followed in order by abdominal migraine (8.3\%), irritable bowel syndrome (6.9\%), and aerophagia (3.1\%). A significantly higher prevalence of FGID was observed in females $(p=0.000)$. No significant difference was observed between the age groups or type of school they attended.

Conclusions: The overall prevalence of FGID in the sample was 30\%, with functional constipation being the most common. These results are similar to those of other prevalence studies reported elsewhere. (Korean J Gastroenterol 2019;73:207-212)

Key Words: Constipation; Developing countries; Epidemiology; Irritable bowel syndrome; Schools

\section{INTRODUCTION}

Functional gastrointestinal disorders (FGIDs) are entities, in which there is an alteration in the interaction between the brain and digestive tract without an organic cause to explain it. Multiple pathophysiological mechanisms have been described, such as motility disturbance, visceral hypersensitivity, altered mucosal and immune function, altered gut microbiota, and altered central nervous system processing. ${ }^{1}$

Observational studies in the pediatric population conducted in countries in Latin American, ${ }^{2-6}$ Asia, ${ }^{7-9}$ North America, ${ }^{10,11}$ Germany, ${ }^{12}$ and Nigeria; ${ }^{13}$ revealed a high prevalence of these disorders in school children and adolescents. The disorders of defecation and irritable bowel syndrome in the FGID were associated with pain. These pathologies are a cause for frequent consultation, ${ }^{14,15}$ and are associated with psychological disorders, such as somatization disorders, ${ }^{8,12}$ emotional problems, ${ }^{12}$ depression, ${ }^{11}$ anxiety, ${ }^{11}$ school absenteeism, and poor school performance. ${ }^{7,8}$ Therefore, identifying these disorders in a timely manner is very important.

FGIDs are the result of interactions between genetic, environmental, dietary, psychological, physiological, and sociocultural factors. Knowing the epidemiology in population studies in different regions, allows an evaluation of the role played by these factors in the prevalence of these disorders. The diagnosis of these disorders is made by the application of validated diagnostic instruments, clinical history, and complete physical examination. The aim of this study was to de-

Received December 28, 2018. Revised February 1, 2019. Accepted February 7, 2019.

(C) This is an open access article distributed under the terms of the Creative Commons Attribution Non-Commercial License (http://creativecommons.org/licenses/ by-nc/4.0) which permits unrestricted non-commercial use, distribution, and reproduction in any medium, provided the original work is properly cited. Copyright $($ C 2019. Korean Society of Gastroenterology.

Correspondence to: Juan Javier Peralta Palmezano, Department of Pediatrics, Universidad Nacional de Colombia, Fundación Hospital de la Misericordia, Avenida Caracas \#1-65, Bogotá, Colombia. Tel: +57-320-365-4101, Fax: +57-1-309-3313, E-mail: jjperaltap@unal.edu.co, ORCID: https://orcid.org/0000-0001-6766-8679

Financial support: None. Conflict of interest: None. 
termine the prevalence of FGID in school children and adolescents in Colombia using the Rome III criteria.

\section{SUBJECTS AND METHODS}

A descriptive, cross-sectional study was conducted in Colombian children from two schools in the department of Cundinamarca, one private and one public. The first (private) school was in Bogotá and the second (public) was in Sibaté. Bogotá is a city located at $4^{\circ} 35^{\prime} 56^{\prime \prime} \mathrm{N} 74^{\circ} 4^{\prime} 51^{\prime \prime} \mathrm{W}$ at a height of 2,640 meters above sea level and with a population of 8 million inhabitants. Sibaté is a city located at $4^{\circ} 29^{\prime} 27^{\prime \prime} \mathrm{N}$ $74^{\circ} 4^{\prime} 51^{\prime \prime} \mathrm{W}$ at a height of 2,600 meters above sea level and with a population of 38,412 inhabitants. The two cities have a similar racial composition with a predominance of mestizos (42.7\%), white Hispanics (36.5\%), black Hispanics (1.5\%), and indigenous $(0.5 \%)$. This is similar to the racial composition in Colombia in the first two groups, mestizos (49\%) and white Hispanics (37\%), but with a difference in the groups of black Hispanics (10.6\%) and indigenous (3.4\%). These two cities were chosen because of the difference in size and population, which helps determine the influence of height and population characteristics on the prevalence of FGIDs. The study was conducted between the months of May and August 2017.

To calculate the sample size, all inhabitants of the two cities in which the schools were located were considered as a population. Another study on the Colombian population in a previous study reported a $29 \%$ prevalence of FGID $^{3}$ with a $\mathrm{Cl}$ of $95 \%$ and an estimation error of 0.05 . The required sample size was 317 subjects.
The protocol was approved by the principals of both schools and the ethics committee of the Fundación Hospital de la Misericordia. Invitations were sent to the parents or caregivers, explaining the reason for the study and informed consent was requested. The following subjects were excluded: students with a history of recent abdominal surgery, those who had organic disorders (neoplastic, endocrinological, metabolic, rheumatological, or organic disorder of the gastrointestinal system), who had frequent ingestion of drugs that could affect the function of the gastrointestinal system (anticholinergic, antihistaminic, corticoids, non-steroidal anti-inflammatory drugs, antiepileptic drugs, antidepressants, laxatives, acid secretion inhibitors, antacids, antispasmodics, and prokinetics), pregnant women, and those who did not respond adequately or did not complete the questionnaire due to lack of understanding or did not want to participate in the study.

They were asked to answer the Spanish version of the Questionnaire on Pediatric Gastrointestinal Symptoms-Rome III Version (S-QPGS-III) self-report form, which has been validated for Spanish-speaking children. ${ }^{16,17}$ During the realization of the questionnaire, the teacher in charge of the room and a member of the research team were present to allay any doubts.

The data was recorded on the Microsoft Excel program and analyzed using the SPSS program (IBM SPSS Statistics for Windows, version 22.0; IBM Corp., Armonk, NY, USA). The frequencies were reported in percentages. The KolmogorovSmirnov test with a Lilliefors correction was performed to determine the normality; the age was not distributed normally.

Table 1. Characteristics of the Students Analyzed

\begin{tabular}{|c|c|c|c|c|c|}
\hline Variable & Total $(n=864)$ & With FGID $(n=259)$ & Without FIGD (n=605) & OR (95\% Cl) & $p$-value ${ }^{a}$ \\
\hline Gender & & & & $0.491(0.364-0.662)$ & 0.000 \\
\hline Male & 426 (49.3) & $96(22.5)$ & $330(77.5)$ & & \\
\hline Female & $438(50.7)$ & $163(37.2)$ & $275(62.8)$ & & \\
\hline Age (years) & & & & $1.092(0.816-1.462)$ & 0.552 \\
\hline 8-12 & 437 (50.6) & 135 (30.9) & 302 (69.1) & & \\
\hline $13-17$ & $427(49.4)$ & $124(29.0)$ & $303(71.0)$ & & \\
\hline School type & & & & $0.733(0.577-1.036)$ & 0.085 \\
\hline Public & 492 (56.9) & $136(27.6)$ & 356 (72.4) & & \\
\hline Private & 372 (43.1) & 123 (33.1) & 249 (66.9) & & \\
\hline
\end{tabular}

Values are presented as $\mathrm{n}(\%)$ unless otherwise indicated.

FGID, functional gastrointestinal disorder; OR, odds ratio; $\mathrm{Cl}$, confidence interval.

${ }^{a}$ Chi-square test. 
A comparison was made between the groups with a Chi-square test and Mann Whitney $U$ test, when appropriate. The OR was calculated to evaluate the effect of potential risk factors, such as sex, age, and type of school, on the prevalence of FGID. P-values $<0.05$ were considered significant.

\section{RESULTS}

Nine hundred twenty-four students were invited to participate in the study (537 from the public school and 387 from the private school), with an age range of eight to 17 years. Sixty students were excluded due to organic diseases, recent abdominal surgery, and ingestion of medications that could affect the gastrointestinal motility or because they not adequately answer the S-QPGS-III (39 students). No significant differences in age or sex were observed between those who were discarded and those who participated in the study.

A total of 864 children with a mean age of $12.5 \pm 2.5$ years (range of eight to 17 years) were analyzed; $50.7 \%$ were female. Four hundred and ninety-two children attended the public school and 372 attended the private school. Table 1 lists the characteristics of the subjects.

Two hundred and fifty-nine children (30\%) met the Rome III criteria for at least one FGID. The mean age in this group was $12.3 \pm 2.7$ years and 163 were women (62.9\%). Sixty-nine (8\%) children presented with two or more FGID. Of the 259 students with a FGID, 190 (73.3\%) had one diagnosis, 57 (22\%) had two, 10 (3.9\%) had three, and two (0.8\%) had four. The most frequent combinations were irritable bowel syndrome+aerophagia, functional constipation+abdominal migraine, functional constipation+aerophagia, and irritable bowel syndrome+abdominal migraine. Table 2 lists the frequency of FGID in the study and Table 3 presents the distribution of the specific diagnoses in students with the most frequent combination of FGID. Functional constipation was the most prevalent disorder (13.2\%), followed in order by abdominal migraine (8.3\%), irritable bowel syndrome (6.9\%), and aerophagia (3.1\%). Table 4 lists the distribution of FGID.

Table 2. Frequency of Results of the Rome III Questionnaire

\begin{tabular}{|c|c|c|c|}
\hline Results & Total $(n=864)$ & Women $(n=438)$ & Men $(n=426)$ \\
\hline Without FGID & $605(70)$ & $275(62.8)$ & $330(77.5)$ \\
\hline With at least one FGID & $259(30)$ & $163(37.2)$ & $96(22.5)$ \\
\hline One FGID & $190(22)$ & $118(26.9)$ & $72(17)$ \\
\hline Two FGID & $57(6.6)$ & $35(8)$ & $22(5)$ \\
\hline Three FGID & $10(1.2)$ & $8(1.8)$ & $2(0.5)$ \\
\hline Four FGID & $2(0.2)$ & $2(0.5)$ & 0 \\
\hline
\end{tabular}

Values are presented as $\mathrm{n}(\%)$.

FGID, functional gastrointestinal disorders.

Table 3. Distribution of Specific Diagnoses in Students with 1, 2, 3 or 4 Functional Gastrointestinal Disorder

\begin{tabular}{|c|c|c|c|c|c|c|c|}
\hline \multicolumn{2}{|c|}{$\begin{array}{l}\text { One diagnoses } \\
\qquad(n=190)\end{array}$} & \multicolumn{2}{|c|}{$\begin{array}{l}\text { Two diagnoses } \\
\qquad(n=57)\end{array}$} & \multicolumn{2}{|c|}{$\begin{array}{l}\text { Three diagnoses } \\
\qquad(n=10)\end{array}$} & \multicolumn{2}{|c|}{$\begin{array}{l}\text { Four diagnose } \\
\qquad(n=2)\end{array}$} \\
\hline IBS & $30(3.5)$ & $\mathrm{FC}+\mathrm{APG}$ & $6(0.69)$ & $\mathrm{FC}+\mathrm{AM}+\mathrm{APG}$ & $1(0.1)$ & $F D+F C+A M+A P G$ & $1(0.1)$ \\
\hline FD & $10(1.2)$ & $\mathrm{FC}+\mathrm{AM}$ & $10(1.2)$ & $\mathrm{FAP}+\mathrm{FC}+\mathrm{CVS}$ & $1(0.1)$ & $I B S+A P G+C V S+A R S$ & $1(0.1)$ \\
\hline FAP & $13(1.5)$ & $\mathrm{FD}+\mathrm{AM}$ & $4(0.5)$ & $F D+F C+A P G$ & $1(0.1)$ & & \\
\hline FAPS & $6(0.7)$ & IBS+AM & $15(1.7)$ & $\mathrm{FD}+\mathrm{FC}+\mathrm{AM}$ & $1(0.1)$ & & \\
\hline AM & $35(4)$ & $\mathrm{IBS}+\mathrm{APG}$ & $8(0,9)$ & $\mathrm{FC}+\mathrm{AM}+\mathrm{ARS}$ & $1(0.1)$ & & \\
\hline FC & $84(9.4)$ & $\mathrm{FD}+\mathrm{APG}$ & $1(0.1)$ & $A M+A P G+C V S$ & $1(0.1)$ & & \\
\hline APG & $1(0.1)$ & $A M+A P G$ & $1(0.1)$ & $I B S+A M+A P G$ & $2(0.23)$ & & \\
\hline CVS & $7(0.8)$ & FAPS+APG & $1(0.1)$ & $\mathrm{IBS}+\mathrm{APG}+\mathrm{CVS}$ & $2(0.23)$ & & \\
\hline ARS & $4(0.5)$ & Others & $11(1.3)$ & & & & \\
\hline
\end{tabular}

Values are presented as $\mathrm{n}(\%)$.

IBS, irritable bowel syndrome; FC, functional constipation; APG, aerophagia; AM, abdominal migraine; FD, functional dyspepsia; FAP, functional abdominal pain; CVS, cyclic vomiting syndrome; ARS, adolescent rumination syndrome; FAPS, functional abdominal pain syndrome. 
A significantly higher prevalence of FGID was observed in girls $(37.2 \%$ vs. $22.5 \%, p=0.000)$. No significant differences in the prevalence of FGID were observed among students 12 years old or younger and more than 12 years old (30.9\% vs. $29 \%, p=0.552$ ). No significant differences in the prevalence of FGID were found among students in the private school compared to the public school (33.1\% vs. $27.6 \%$, $p=0.085$ ).

\section{DISCUSSION}

This is the second prevalence study of FGID carried out in a school and adolescent population in Colombia with a previous study conducted in the city of Pasto. ${ }^{3}$ In this study, the overall prevalence of FGID was $30 \%$ with a predominance of functional constipation (13.2\%), abdominal migraine (8.3\%), irritable bowel syndrome (6.9\%), and aerophagia (3.1\%). Women had a significantly higher prevalence in the overall FGID and specifically in irritable bowel syndrome, abdominal migraine, aerophagia, and cyclic vomiting syndrome. No significant difference was observed in the prevalence of FGID at different ages or the type of school.

The results of the prevalence studies of FGID depend on the person who answers the questionnaire (patient or parents), instrument used (Rome II or Rome III), ${ }^{9}$ and if they are population studies $(9.9-29 \%)^{18}$ or were carried out in spe- cialized clinics (87\%). ${ }^{19}$ One of the objectives of population studies is to identify the differences that can help explain how environmental, dietary, genetic, and sociocultural factors influence diseases. Therefore, it is important to compare studies with others that have similar methodologies.

Similar results were obtained when the overall prevalence of FGIDs in this study was compared with other studies, e.g., the results of the study in the city of Pasto, Colombia (29\%), ${ }^{3}$ Panama (28.7\%), ${ }^{6}$ Mexico (27.3\%), ${ }^{5}$ Ecuador (22.8\%), ${ }^{2}$ and Sri Lanka (28.8\%). ${ }^{9}$ Some similarity was noted when the prevalence of each disorder was analyzed separately in all studies in countries of Latin America; functional constipation was the most prevalent disorder followed by functional abdominal pain disorders. ${ }^{2-6}$ Although functional abdominal pain disorders are more frequent in studies conducted in Asian countries. ${ }^{7-9}$ These findings could be explained by similar genetic, environmental, and sociocultural factors in these regions.

These results show a higher prevalence of aerophagia and abdominal migraine, the latter being the second most frequent disorder. These findings may have several explanations. With the change of the Rome II to Rome III criteria, the prevalence of abdominal migraine increased from $5.7 \%$ to $23 \%$ and so did the proportion of patients who had the criteria for two or more FGIDs (4.1\% Rome II vs. $13 \%$ Rome III). ${ }^{20}$ This increase in prevalence was due partly to changes in the criteria of the symptoms associated with the episodes of abdominal

Table 4. Distribution of the Functional Gastrointestinal Disorder (One or More) in the Population that Answered the Rome III Questionnaire ( $\mathrm{n}=864)$

\begin{tabular}{|c|c|c|c|c|}
\hline Functional gastrointestinal disorder & Value & Women & Men & $p$-value ${ }^{a}$ \\
\hline \multicolumn{5}{|l|}{ Functional abdominal pain disorders } \\
\hline Irritable bowel syndrome & $60(6.9)$ & $41(9.4)$ & $19(4.5)$ & 0.005 \\
\hline Functional dyspepsia & $21(2.4)$ & $15(3.4)$ & $6(1.4)$ & 0.054 \\
\hline Functional abdominal pain & $14(1.6)$ & $10(2.3)$ & $4(0.9)$ & 0.118 \\
\hline Functional abdominal pain syndrome & $9(1)$ & $4(0.9)$ & $5(1.2)$ & 0.706 \\
\hline Abdominal migraine & $72(8.3)$ & $50(11.4)$ & $22(5.2)$ & 0.001 \\
\hline \multicolumn{5}{|l|}{ Functional defecation disorders } \\
\hline Functional constipation & $114(13.2)$ & $60(13.7)$ & $54(12.7)$ & 0.657 \\
\hline Nonretentive fecal incontinence & 0 & 0 & 0 & \\
\hline \multicolumn{5}{|l|}{ Functional nausea and vomiting disorders } \\
\hline Aerophagia & $27(3.1)$ & $20(4.6)$ & $7(1.6)$ & 0.014 \\
\hline Cyclic vomiting syndrome & $15(1.7)$ & $12(2.7)$ & $3(0.7)$ & 0.022 \\
\hline Adolescent rumination syndrome & $10(1.2)$ & $8(1.8)$ & $2(0.5)$ & 0.062 \\
\hline
\end{tabular}

Values are presented as $\mathrm{n}(\%)$.

Percentages do not sum to 100 because some patients met criteria for more than 1 functional gastrointestinal disorder.

${ }^{\mathrm{a}}$ Chi-square test. 
pain. Patients with irritable bowel syndrome, functional constipation, and functional abdominal pain also present with symptoms that are part of the diagnostic criteria of abdominal migraine, such as anorexia, nausea, vomiting, headache and photophobia. $^{21,22}$ In addition, the characteristics of the abdominal pain of these other disorders may be similar to those of abdominal migraines. ${ }^{22}$ The Rome III questionnaire for the diagnosis of abdominal migraine, when compared with a physician's evaluation, has a negative predictive value of $100 \%$ and a positive predictive value of $7.7 \%$. Therefore, children with other FGIDs are misclassified frequently as abdominal migraine using the de Rome III questionnaire. ${ }^{22}$

In the present study, $26.7 \%$ of students with FGID had two or more diagnoses; $51 \%$ of abdominal migraines and $96 \%$ of aerophagia were associated with other diagnoses, mainly with irritable bowel syndrome, functional constipation and functional dyspepsia. Although a study in children with aerophagia showed a smaller association with other FGIDs $(23.9 \%),{ }^{23}$ the independent existence of aerophagia was questioned. A study in adults showed that patients with aerophagia also have abdominal pain, nausea, vomiting, and early satiety. On the other hand, these symptoms were less frequent than those with functional dyspepsia. ${ }^{24}$ Although this shows that aerophagia is a clinically distinct upper FGID, this study was retrospective and did not compare aerophagia with irritable bowel syndrome.

Women present a significantly higher frequency of all FGID and in subgroups, such as irritable bowel syndrome, abdominal migraine, aerophagia, and cyclic vomiting syndrome. Children under 12 years of age and those attending private school had a higher prevalence of FGID, but this was not significant. When comparing with other studies, contradictory results are found in the analysis of these potential risk factors. Most of the studies did not show significant differences, but in others, there was a higher prevalence in females, ${ }^{7}$ which increased with age or was higher in children $\leq 12$ years and in private institutions. ${ }^{4}$ Other measures, such as stressors, other socioeconomic conditions or family characteristics, were not evaluated so considering only sex or the type of school as a risk factor is difficult.

The greatest strength of the study was the sample size. Two schools with two populations with similar demographic characteristics were included so that an adequate comparison could be made.
The limitations of this study are that there was no gathering of other demographic and family data, which serves as potential risk factor for the development of FGID. The sample is limited only to the population of a region of the country, so the data cannot be generalized to the entire Colombian population, and it should be considered a study at a national level. The diagnosis of the FGID was made by the interpretation of the S-QPGS-III answered by the children, avoiding an interrogation and complete physical examination to exclude other pathologies. In addition, the answers could have been subjective with the risk of errors in the results. The information from the parents was not considered. Finally, the S-QPGS-III was validated for children over 10 years of age, even though the translation into Spanish and validated for the study population has already been applied to other countries by the The Functional International Digestive Epidemiological Research Survey group, ${ }^{2-6}$ with similar populations.

In conclusion, a high prevalence of FGID was found in Colombian children with a higher prevalence of functional constipation, irritable bowel syndrome, abdominal migraine, and aerophagia. Females had a significantly higher prevalence of FGID, without significant differences by age groups or by type of school. These results are similar to those presented in other Latin American countries. This study can be replicated in more regions of the country, with more complete sociodemographic information and the implementation of the Rome IV questionnaire.

\section{REFERENCES}

1. Drossman DA. Functional gastrointestinal disorders and the Rome IV Process. In: Drossman DA, Chang L, Chey WD, Kellow J, Tack J, Whitehead WE, eds. ROME IV functional pediatric gastrointestinal disorders: disorders of gut-brain interaction. 1st ed. Raleigh: The Rome Foundation Inc., 2017:2-32.

2. Játiva E, Velasco-Benítez CA, Koppen IJ, Játiva-Cabezas Z, Saps M. Prevalence of functional gastrointestinal disorders in schoolchildren in ecuador. J Pediatr Gastroenterol Nutr 2016;63:25-28.

3. Saps M, Nichols-Vinueza DX, Rosen JM, Velasco-Benítez CA. Prevalence of functional gastrointestinal disorders in Colombian school children. J Pediatr 2014;164:542-545.e1.

4. Zablah R, Velasco-Benítez CA, Merlos I, Bonilla S, Saps M. Prevalence of functional gastrointestinal disorders in schoolaged children in El Salvador. Rev Gastroenterol Mex 2015;80: 186-191.

5. Dhroove G, Saps M, Garcia-Bueno C, Leyva Jiménez A, RodriguezReynosa LL, Velasco-Benítez CA. Prevalence of functional gastro- 
intestinal disorders in Mexican schoolchildren. Rev Gastroenterol Mex 2017;82:13-18.

6. Lu PL, Saps M, Chanis RA, Velasco-Benítez CA. The prevalence of functional gastrointestinal disorders in children in Panama: a school-based study. Acta Paediatr 2016;105:e232-e236.

7. Sagawa T, Okamura S, Kakizaki S, Zhang Y, Morita K, Mori M. Functional gastrointestinal disorders in adolescents and quality of school life. J Gastroenterol Hepatol 2013;28:285-290.

8. Bhatia V, Deswal S, Seth S, Kapoor A, Sibal A, Gopalan S. Prevalence of functional gastrointestinal disorders among adolescents in Delhi based on Rome III criteria: a school-based survey. Indian J Gastroenterol 2016;35:294-298.

9. Devanarayana NM, Adhikari C, Pannala W, Rajindrajith S. Prevalence of functional gastrointestinal diseases in a cohort of Sri Lankan adolescents: comparison between Rome II and Rome III criteria. J Trop Pediatr 2011;57:34-39.

10. Lewis ML, Palsson OS, Whitehead WE, van Tilburg MAL. Prevalence of functional gastrointestinal disorders in children and adolescents. J Pediatr 2016;177:39-43.e3.

11. Hyams JS, Burke G, Davis PM, Rzepski B, Andrulonis PA. Abdominal pain and irritable bowel syndrome in adolescents: a community-based study. J Pediatr 1996;129:220-226.

12. Gulewitsch MD, Enck P, Schwille-Kiuntke J, Weimer K, Schlarb AA. Rome III criteria in parents' hands: pain-related functional gastrointestinal disorders in community children and associations with somatic complaints and mental health. Eur J Gastroenterol Hepatol 2013;25:1223-1229.

13. Udoh E, Devanarayana NM, Rajindrajith S, Meremikwu M, Benninga MA. Abdominal pain-predominant functional gastrointestinal disorders in adolescent nigerians. J Pediatr Gastroenterol Nutr 2016;62:588-593.

14. Rouster AS, Karpinski AC, Silver D, Monagas J, Hyman PE. Functional gastrointestinal disorders dominate pediatric gastroenterology outpatient practice. J Pediatr Gastroenterol Nutr 2016;62:847-851.

15. Talachian E, Bidari A, Zahmatkesh H. Abdominal pain-related functional gastrointestinal disorders based on Rome III criteria in a pediatric gastroenterology clinic. Med J Islam Repub Iran 2015;29:247. eCollection 2015.

16. Velasco CA, Nichols-Vinueza D, Saps M. Spanish version of the questionnaire on pediatric gastrointestinal symptoms-Rome III (QPGSRIII). J Pediatr Gastroenterol Nutr 2011;53(Suppl 1):E65.

17. Saps M, Velasco CA, Nichols-Vinueza D. Validation of the Rome III criteria. High internal consistency of the questionnaire of pediatric gastrointestinal symptoms (Spanish version). J Pediatr Gastroenterol Nutr 2012;55(Suppl 1):E36-E37.

18. Boronat AC, Ferreira-Maia AP, Matijasevich A, Wang YP. Epidemiology of functional gastrointestinal disorders in children and adolescents: a systematic review. World J Gastroenterol 2017;23:3915-3927.

19. Helgeland H, Flagstad G, Grøtta J, Vandvik PO, Kristensen H, Markestad T. Diagnosing pediatric functional abdominal pain in children (4-15 years old) according to the Rome III criteria: results from a Norwegian prospective study. J Pediatr Gastroenterol Nutr 2009;49:309-315.

20. Baber KF, Anderson J, Puzanovova M, Walker LS. Rome II versus Rome III classification of functional gastrointestinal disorders in pediatric chronic abdominal pain. J Pediatr Gastroenterol Nutr 2008;47:299-302.

21. Devanarayana NM, Mettananda S, Liyanarachchi C, et al. Abdominal pain-predominant functional gastrointestinal diseases in children and adolescents: prevalence, symptomatology, and association with emotional stress. J Pediatr Gastroenterol Nutr 2011;53:659-665.

22. Saps M, Sztainberg M, Pusatcioglu C, Chogle A. Tu2007 Accuracy of diagnosis for abdominal migraine in children. Gastroenterology 2014;146(Suppl 1):S897.

23. Devanarayana NM, Rajindrajith S. Aerophagia among Sri Lankan schoolchildren: epidemiological patterns and symptom characteristics. J Pediatr Gastroenterol Nutr 2012;54:516-520.

24. Chitkara DK, Bredenoord AJ, Rucker MJ, Talley NJ. Aerophagia in adults: a comparison with functional dyspepsia. Aliment Pharmacol Ther 2005;22:855-858. 